Research Paper

\title{
Impact of ADAM10 gene polymorphisms on hepatocellular carcinoma development and clinical characteristics
} \author{
Yang 2,10 , Ying-Erh Chou $8,10, \bowtie$

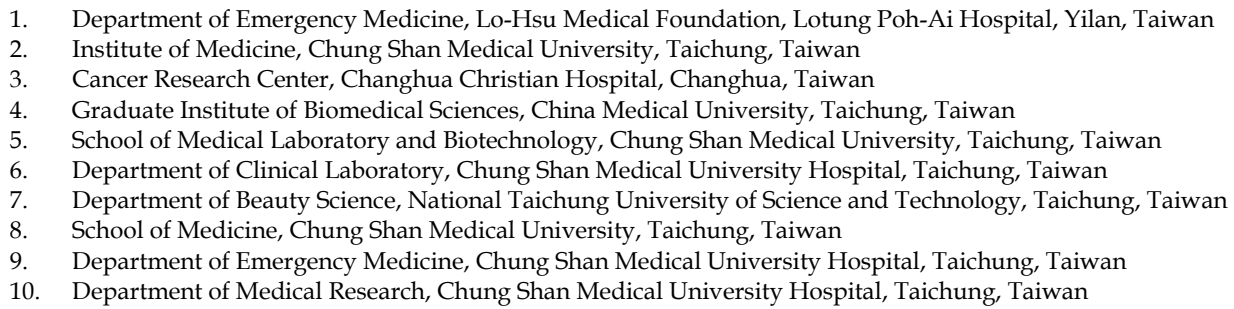

Jr-Shiang Shiu1, Ming-Ju Hsieh2,3,4, Hui-Ling Chiou ${ }^{5,6}$, Hsiang-Ling Wang7, Chao-Bin Yeh ${ }^{8,9}$, Shun-Fa

$\triangle$ Corresponding author: Ying-Erh Chou, Ph.D. School of Medicine, Chung Shan Medical University, Taichung 402, Taiwan; Tel: +886-4-24739595 ext. 34253; Fax: +886-4-24723229; E-mail: intointo814@gmail.com

(C) Ivyspring International Publisher. This is an open access article distributed under the terms of the Creative Commons Attribution (CC BY-NC) license (https://creativecommons.org/licenses/by-nc/4.0/). See http://ivyspring.com/terms for full terms and conditions.

Received: 2018.05.04; Accepted: 2018.07.29; Published: 2018.08.10

\begin{abstract}
A disintegrin and metalloprotease (ADAM) family proteins are type-I transmembrane glycoproteins with multiple functions in cell adhesion, migration, proteolysis and signaling. ADAM10 is a member of the ADAM family reportedly involved in cancer progression and has been shown to be overexpressed in hepatocellular carcinoma ( $\mathrm{HCC}$ ) tissues and significantly associated with tumor progression and shortened survival. This study investigated ADAM10's single nucleotide polymorphisms (SNPs) and their association to HCC development and regulation. Real-time polymerase chain reaction was used to analyze five SNPs of ADAM10 in 333 patients with HCC and 1196 controls without cancer. The results indicated that of the 333 patients with HCC, those who carried ADAM10 rs514049 (AC + CC) variants had a higher risk of developing lymph node metastasis (odds ratio [OR] = 5.087, $\mathrm{p}=0.027$ ), and those who carried ADAM10 rs653765 (GA + $A A)$ variants had a higher risk of developing distant metastasis $(O R=3.346, p=0.020)$ and higher levels of $\alpha$-fetoprotein. In conclusion, our study demonstrated that the SNPs of ADAM10 are involved in HCC progression. ADAM10 SNPs may be used as therapeutic targets to evaluate poor prognoses for HCC.
\end{abstract}

Key words: Hepatocellular carcinoma; A disintegrin and metalloprotease 10; polymorphism

\section{Introduction}

Hepatocellular carcinoma (HCC) is a major malignancy and the second most prevalent cause of cancer deaths worldwide $[1,2]$. Between $60 \%$ and $70 \%$ of patients with HCC experience distant metastasis or recurrence within 5 years, even when curative interventions or treatments are performed [3, 4]. Although clinical approaches to managing patients with HCC such as clinicopathologic parameters, serologic tumor markers, and radiologic modalities have been used, the prognosis and evaluation of therapeutic response for HCC remains poor and limited [5-7].

The ADAMs (a disintegrin and metalloproteinase) is a family of multifunctional proteins implicated in cell adhesion and proteolysis [8, 9]. ADAM10, a member of the ADAM family, is involved 
in aspects of cancer progression such as tumor development, cell migration, and metastasis with its characteristic proteolytic shedding to cell surface proteins $[10,11]$. Moreover, ADAM10 overexpression may play a role in carcinogenesis and tumor cell proliferation in oral squamous cell carcinoma $[12,13]$. In colon cancer, ADAM10 was found to be involved in cleaving and shedding a transmembrane cell adhesion molecule L1's extracellular domain, and this phenomenon was suggested as useful for colon cancer detection and as a target for cancer therapy [14]. In patients with HCC, ADAM10 was shown to be overexpressed in HCC tissues and significantly associated with tumor progression and shortened survival [15]. This evidence collectively implies the potential role of ADAM10 as a tumor marker in cancer evolution and treatment evaluation.

The human ADAM10 gene contains 16 exons interrupted by 15 introns and is located on chromosome 15 at position 15q21.3-q23 [16]. Previous studies have discussed the potential role of ADAM10 single nucleotide polymorphisms (SNPs) in disease progression and regulation such as Alzheimer's disease (AD) and severe sepsis [17-19]. However, the exact role of ADAM10 SNPs in cancer progression or HCC has not been thoroughly investigated. Thus, we investigated ADAM10 SNPs role in HCC susceptibility and attempted to elucidate the correlations of these SNPs in HCC development and regulation.

\section{Materials and Methods}

\section{Study subjects}

The study group consecutively recruited 333 patients (235 men and 98 women) during 2007-2015 at Chung Shan Medical University Hospital in Taichung, Taiwan. The 1196 cancer-free controls (838 men and 358 women) were selected from the Taiwan Biobank. We recruit the patients with only HCC in our study. Patients and the normal controls with any histories of other cancers were excluded. The information and exposure to alcohol drinking, cigarette smoking was administrated with a questionnaire for both the controls and the study group and classified into "ever user" or "never user". The medical information of the study HCC subjects such as TNM clinical staging, lymph node metastasis, tumor size, distant metastasis, Child-Pugh grade, vascular invasion, HBsAg, Anti-HCV and liver cirrhosis was obtained from their medical records. Written informed consent was obtained from each participant enrolled in this study. This study was approved by the Institutional Review Board of Chung Shan Medical University Hospital.

\section{Sample preparation and DNA extraction}

The genomic DNA was extracted from the peripheral blood specimens collected from HCC patients and normal controls. The whole blood samples were placed in tubes containing EDTA and were instantly centrifuged $3000 \mathrm{rpm}, 10$ minutes. By using a QIAamp DNA blood mini kits, the DNA extraction was performed to the buffy coats extracted from the whole blood specimens according to manufacturer's instruction. Extracted DNA was dissolved in Tris-EDTA (TE) buffer and used as template in the process of polymerase chain reactions (PCRs).

\section{Selection of ADAM10 SNPs}

A total of five SNPs rs514049, rs653765, rs383902, rs2054096, and rs2305421 in ADAM10 were selected from the International HapMap Project data for our current study. The ADAM10 SNPs rs514049 in the promoter region was found significantly associated with APPa (amyloid precursor protein a) levels in Alzheimer's disease. [20]. The rs653765 polymorphism, which is also located in the promoter region of ADAM10, was suggested to be associated with the development of severe sepsis [17].

The ADAM10 SNPs rs383902 was selected in this study because it was associated with conduct disorder using a family-based association study [21]. The rs2054096 was associated with diabetic nephropathy in type 1 diabetes among white individuals before adjustment for multiple testing [22]. In a study of Northern Han Chinese population, the rs2305421 polymorphism in ADAM10 gene was suggested to modify the risk for LOAD (late-onset Alzheimer's disease) [18].

\section{ADAM10 SNPs genotyping}

Assessment of allelic discrimination for the ADAM10 rs514049 (assay IDs: C__912760_10), rs653765 (assay IDs: C___912761_10), rs383902 (assay IDs: C_2412147_10), rs2054096 (assay IDs: C_12081660_10), and rs2305421 (assay IDs: C__2069253_1_) SNP was performed by using the TaqMan assay with an ABI StepOnePlus ${ }^{\mathrm{TM}}$ Real-Time PCR System. The collected data were further evaluated with SDS version 3.0 software (Applied Biosystems, Foster City, CA, USA).

\section{Statistical analysis}

Mann-Whitney U test or Fisher's exact test was used between the healthy controls and patients with HCC to compare their age, gender, cigarette smoking, alcohol drinking, HBsAg, anti-HCV, tumor stage, tumor $\mathrm{T}$ status, lymph node status, metastasis, Child-Pugh grade, and liver cirrhosis. $\mathrm{p}<0.05$ was 
considered that a significant does exist. The odds ratio and $95 \%$ CIs of the association between the genotype frequencies and HCC risk and the clinical pathological characteristics was estimated by logistic regression models. All of the data in this study were analyzed on SAS statistical software (Version 9.1, 2005; SAS Institute, Cary, NC).

\section{Results}

Table 1 presents the distribution of demographic characteristics in 1196 controls and 333 patients with HCC. By analyzing these demographic characteristics, we observed that $14.1 \%(169 / 1196)$ of the controls and $36.6 \%(122 / 333)$ of the patients with HCC drank alcohol. Significant distributional differences were observed for age $(p<0.001)$, HBsAg $(p<0.001)$, and anti-HCV $(\mathrm{p}<0.001)$ between the controls and patients with HCC.

Table 1. The distributions of demographical characteristics in 1196 controls and 333 patients with HCC.

\begin{tabular}{|c|c|c|c|}
\hline Variable & Controls $(\mathrm{N}=1196)$ & Patients $(\mathrm{N}=333)$ & $\mathrm{p}$ value \\
\hline \multicolumn{4}{|l|}{ Age (yrs) } \\
\hline$<61$ & $556(46.5 \%)$ & $142(42.6 \%)$ & $\mathrm{p}=0.213$ \\
\hline$\geqq 61$ & $640(53.5 \%)$ & $191(57.4 \%)$ & \\
\hline \multicolumn{4}{|l|}{ Gender } \\
\hline Male & $838(70.1 \%)$ & $235(70.6 \%)$ & $p=0.859$ \\
\hline Female & $358(29.9 \%)$ & $98(29.4 \%)$ & \\
\hline \multicolumn{4}{|c|}{ Cigarette smoking } \\
\hline No & $725(60.6 \%)$ & $202(60.7 \%)$ & $\mathrm{p}=0.989$ \\
\hline Yes & $471(39.4 \%)$ & $131(39.3 \%)$ & \\
\hline \multicolumn{4}{|c|}{ Alcohol drinking } \\
\hline No & $1027(85.9 \%)$ & $211(63.4 \%)$ & $\mathrm{p}<0.001^{*}$ \\
\hline Yes & $169(14.1 \%)$ & $122(36.6 \%)$ & \\
\hline \multicolumn{4}{|l|}{ HBsAg } \\
\hline Negative & $1051(87.9 \%)$ & $197(59.2 \%)$ & $\mathrm{p}<0.001^{*}$ \\
\hline Positive & $145(12.1 \%)$ & $136(40.8 \%)$ & \\
\hline \multicolumn{4}{|l|}{ Anti-HCV } \\
\hline Negative & $1143(95.6 \%)$ & $178(53.5 \%)$ & $\mathrm{p}<0.001^{*}$ \\
\hline Positive & $53(4.4 \%)$ & $155(46.5 \%)$ & \\
\hline \multicolumn{4}{|l|}{ Stage } \\
\hline $\mathrm{I}+\mathrm{II}$ & & $228(68.5 \%)$ & \\
\hline $\mathrm{III}+\mathrm{IV}$ & & $105(31.5 \%)$ & \\
\hline \multicolumn{4}{|c|}{ Tumor T status } \\
\hline $\mathrm{T} 1+\mathrm{T} 2$ & & $230(69.1 \%)$ & \\
\hline $\mathrm{T} 3+\mathrm{T} 4$ & & $103(30.9 \%)$ & \\
\hline \multicolumn{4}{|c|}{ Lymph node status } \\
\hline No & & $324(97.3 \%)$ & \\
\hline $\mathrm{N} 1+\mathrm{N} 2+\mathrm{N} 3$ & & $9(2.7 \%)$ & \\
\hline \multicolumn{4}{|l|}{ Metastasis } \\
\hline M0 & & $317(95.2 \%)$ & \\
\hline M1 & & $16(4.8 \%)$ & \\
\hline \multicolumn{4}{|c|}{ Child-Pugh grade } \\
\hline 0 or $\mathrm{A}$ & & $255(76.6 \%)$ & \\
\hline B or C & & $78(23.4 \%)$ & \\
\hline \multicolumn{4}{|c|}{ Liver cirrhosis } \\
\hline Negative & & $59(17.7 \%)$ & \\
\hline Positive & & $274(82.3 \%)$ & \\
\hline
\end{tabular}

Mann-Whitney U test or Fisher's exact test was used between healthy controls and patients with HCC. ${ }^{*} p$ value $<0.05$ as statistically significant.

The genotyping and allele frequency of ADAM10 SNPs in the patients with HCC and healthy controls are shown in Table 2. In our recruited control group, the frequencies of ADAM10 rs514049 A/C ( $\chi^{2}$ value: $0.858, \mathrm{p}=0.651)$, rs653765 $\mathrm{G} / \mathrm{A}\left(\chi^{2}\right.$ value: 1.036 , $\mathrm{p}=0.596)$, rs383902 T/C ( $\chi^{2}$ value: $\left.0.104, \mathrm{p}=0.949\right)$, rs2054096 ( $\chi^{2}$ value: $\left.0.020, p=0.990\right)$ and $r s 2305421\left(\chi^{2}\right.$ value: $0.664, p=0.717)$ were in Hardy-Weinberg equilibrium, respectively. ADAM10 genetic polymorphisms rs514049, rs653765, rs383902, rs2054096, and rs2305421 had the highest distribution frequencies in the controls and patients with HCC; these polymorphisms were homozygous for AA, homozygous for GG, homozygous for TT, heterozygous for TA, and heterozygous for AG, respectively. After adjustment for several variables such as alcohol consumption, $\mathrm{HBsAg}$, and anti-HCV, no significant differences were observed for the patients with HCC among the rs514049, rs653765, rs383902, rs2054096, and rs2305421 polymorphisms of the ADAM10 gene and those with the wild-type (WT) gene (Table 2).

Table 2. Genotyping and allele frequency of ADAMIO single nucleotide polymorphism (SNP) in HCC and normal controls.

\begin{tabular}{|c|c|c|c|c|}
\hline Variable & $\begin{array}{l}\text { Controls } \\
(\mathrm{N}=1196)(\%)\end{array}$ & $\begin{array}{l}\text { Patients } \\
(\mathrm{N}=333)(\%)\end{array}$ & OR $(95 \% \mathrm{CI})$ & $\operatorname{AOR}(95 \% \mathrm{CI})^{\mathrm{a}}$ \\
\hline \multicolumn{5}{|l|}{ rs514049 } \\
\hline AA & $1070(89.5 \%)$ & $301(90.4 \%)$ & 1.000 (reference) & 1.000 (reference) \\
\hline $\mathrm{AC}$ & $124(10.3 \%)$ & $32(9.6 \%)$ & $0.917(0.609-1.381)$ & $0.756(0.436-1.311)$ \\
\hline $\mathrm{CC}$ & $2(0.2 \%)$ & $0(0.0 \%)$ & - & - \\
\hline $\begin{array}{l}\mathrm{AC}+\mathrm{CC} \\
\text { rs653765 }\end{array}$ & $126(10.5 \%)$ & $32(9.6 \%)$ & $0.903(0.600-1.358)$ & $0.748(0.432-1.296)$ \\
\hline GG & $818(68.4 \%)$ & $236(70.9 \%)$ & 1.000 (reference) & 1.000 (reference) \\
\hline GA & $336(28.1 \%)$ & $88(26.4 \%)$ & $0.908(0.689-1.196)$ & $0.875(0.613-1.248)$ \\
\hline AA & $42(3.5 \%)$ & $9(2.7 \%)$ & $0.743(0.356-1.548)$ & $0.998(0.409-2.432)$ \\
\hline $\mathrm{GA}+\mathrm{AA}$ & $378(31.5)$ & $97(29.1 \%)$ & $0.889(0.682-1.160)$ & $0.887(0.630-1.248)$ \\
\hline \multicolumn{5}{|l|}{ rs383902 } \\
\hline TT & $864(72.2 \%)$ & $249(74.8 \%)$ & 1.000 (reference) & 1.000 (reference) \\
\hline $\mathrm{TC}$ & $307(25.7 \%)$ & $78(23.4 \%)$ & $0.882(0.662-1.173)$ & $0.842(0.582-1.217)$ \\
\hline $\mathrm{CC}$ & $25(2.1 \%)$ & $6(1.8 \%)$ & $0.833(0.338-2.053)$ & $0.885(0.281-2.791)$ \\
\hline $\mathrm{TC}+\mathrm{CC}$ & $332(27.8 \%)$ & $84(25.2 \%)$ & $0.878(0.665-1.159)$ & $0.845(0.590-1.209)$ \\
\hline \multicolumn{5}{|l|}{ rs2054096 } \\
\hline $\mathrm{TT}$ & $341(28.5 \%)$ & $91(27.3 \%)$ & 1.000 (reference) & 1.000 (reference) \\
\hline TA & $598(50.0 \%)$ & $182(54.7 \%)$ & $1.140(0.858-1.516)$ & $1.223(0.845-1.770)$ \\
\hline AA & $257(21.5 \%)$ & $60(18.0 \%)$ & $0.875(0.608-1.259)$ & $0.830(0.515-1.338)$ \\
\hline $\mathrm{TA}+\mathrm{AA}$ & $855(71.5 \%)$ & $242(72.7 \%)$ & $1.061(0.808-1.392)$ & $1.106(0.776-1.575)$ \\
\hline \multicolumn{5}{|l|}{ rs2305421 } \\
\hline AA & $435(36.4 \%)$ & $110(33.0 \%)$ & 1.000 (reference) & 1.000 (reference) \\
\hline AG & $561(46.9 \%)$ & $166(49.9 \%)$ & $1.170(0.892-1.535)$ & $1.239(0.872-1.759)$ \\
\hline GG & $200(16.7 \%)$ & $35(17.1 \%)$ & $1.127(0.785-1.617)$ & $1.121(0.705-1.782)$ \\
\hline$A G+G G$ & $761(63.6 \%)$ & $201(67.0 \%)$ & $1.159(0.896-1.498)$ & $1.206(0.866-1.679)$ \\
\hline
\end{tabular}

To clarify the role of ADAM10 genetic polymorphisms in HCC status in relation to clinical stage, tumor size, lymph node metastasis, distant metastasis, vascular invasion, Child-Pugh grade, $\mathrm{HBsAg}$, anti-HCV, and liver cirrhosis, the distribution frequency of clinical status and ADAM10 genotype frequency in the patients with HCC was estimated. The rs383902, rs2054096, and rs2305421 genetic polymorphisms showed no significant association with clinicopathologic status. However, the 333 
patients with HCC who carried the polymorphic rs514049 gene had a higher risk of lymph node metastasis (odds ratio [OR] $=5.087,95 \%$ confidence interval $[\mathrm{CI}]=1.209-21.415, \mathrm{p}=0.027)$ than did those carrying the rs514049 WT gene, but no differences were observed for clinical stage, tumor size, distant metastasis, vascular invasion, Child-Pugh grade, $\mathrm{HBsAg}$, anti-HCV, or liver cirrhosis (Table 3). A similar result was observed for the patients with HCC who carried the polymorphic rs653765 gene, who had a higher risk of distant metastasis $(\mathrm{OR}=3.346,95 \% \mathrm{CI}$ = 1.209-9.259); however, no differences were observed for other clinical statuses (Table 4).

Table 3. Odds ratio (OR) and $95 \%$ confidence interval $(\mathrm{Cl})$ of clinical status and ADAMIO rs514049 genotypic frequencies in 333 HCC patients.

\begin{tabular}{|c|c|c|c|c|}
\hline \multirow[t]{2}{*}{ Variable } & \multicolumn{4}{|c|}{ Genotypic frequencies } \\
\hline & $\begin{array}{l}\text { AA } \\
(\mathrm{N}=301)\end{array}$ & $\begin{array}{l}\mathrm{AC}+\mathrm{CC} \\
(\mathrm{N}=32)\end{array}$ & OR (95\% CI) & $\operatorname{AOR}(95 \% \mathrm{CI})^{\mathrm{a}}$ \\
\hline \multicolumn{5}{|l|}{ Clinical Stage } \\
\hline Stage I/II & $207(68.8 \%)$ & $21(65.6 \%)$ & 1.00 & 1.00 \\
\hline Stage III/IV & $94(31.2 \%)$ & $11(34.4 \%)$ & $1.153(0.535-2.489)$ & $1.158(0.536-2.504)$ \\
\hline \multicolumn{5}{|l|}{ Tumor size } \\
\hline$\leqq \mathrm{T} 2$ & $209(69.4 \%)$ & $21(65.6 \%)$ & 1.00 & 1.00 \\
\hline$>\mathrm{T} 2$ & $92(30.6 \%)$ & $11(34.4 \%)$ & $1.190(0.551-2.569)$ & $1.189(0.550-2.572)$ \\
\hline \multicolumn{5}{|l|}{$\begin{array}{l}\text { Lymph node } \\
\text { metastasis }\end{array}$} \\
\hline No & $295(98.0 \%)$ & $29(90.6 \%)$ & 1.00 & 1.00 \\
\hline Yes & $6(2.0 \%)$ & $3(9.4 \%)$ & $\begin{array}{l}5.087 \\
(1.209-21.415)^{b}\end{array}$ & $\begin{array}{l}4.405 \\
(1.015-19.127)^{c}\end{array}$ \\
\hline \multicolumn{5}{|c|}{ Distant metastasis } \\
\hline No & $287(95.3 \%)$ & $30(93.7 \%)$ & 1.00 & 1.00 \\
\hline Yes & $14(4.7 \%)$ & $2(6.3 \%)$ & $1.367(0.296-6.303)$ & $1.244(0.267-5.802)$ \\
\hline \multicolumn{5}{|c|}{ Vascular invasion } \\
\hline No & $250(83.1 \%)$ & $26(81.2 \%)$ & 1.00 & 1.00 \\
\hline Yes & $51(16.9 \%)$ & $6(18.8 \%)$ & $1.131(0.443-2.888)$ & $1.119(0.437-2.864)$ \\
\hline \multicolumn{5}{|c|}{ Child-Pugh grade } \\
\hline 0 or $\mathrm{A}$ & $230(76.4 \%)$ & $25(78.1 \%)$ & 1.00 & 1.00 \\
\hline $\mathrm{B}$ or $\mathrm{C}$ & $71(23.6 \%)$ & $7(21.9 \%)$ & $0.907(0.376-2.185)$ & $0.889(0.368-2.147)$ \\
\hline \multicolumn{5}{|l|}{ HBsAg } \\
\hline Negative & $177(58.8 \%)$ & $20(62.5 \%)$ & 1.00 & 1.00 \\
\hline Positive & $124(41.2 \%)$ & $12(37.5 \%)$ & $0.856(0.404-1.816)$ & $0.855(0.402-1.816)$ \\
\hline \multicolumn{5}{|l|}{ Anti-HCV } \\
\hline Negative & $164(54.5 \%)$ & $14(43.7 \%)$ & 1.00 & 1.00 \\
\hline Positive & $137(45.5 \%)$ & $18(56.3 \%)$ & $1.540(0.739-3.209)$ & $1.559(0.747-3.257)$ \\
\hline \multicolumn{5}{|l|}{ Liver cirrhosis } \\
\hline Negative & $54(17.9 \%)$ & $5(15.6 \%)$ & 1.00 & 1.00 \\
\hline Positive & $247(82.1 \%)$ & $27(84.4 \%)$ & $1.181(0.435-3.205)$ & $1.151(0.423-3.133)$ \\
\hline \multicolumn{5}{|c|}{$\begin{array}{l}\text { The ORs with analyzed by their } 95 \% \text { CIs were estimated by logistic regression } \\
\text { models. }\end{array}$} \\
\hline \multicolumn{5}{|c|}{$\begin{array}{l}\text { > T2: multiple tumor more than } 5 \mathrm{~cm} \text { or tumor involving a major branch of the } \\
\text { portal or hepatic vein(s) }\end{array}$} \\
\hline \multicolumn{5}{|c|}{$\begin{array}{l}{ }^{*} \mathrm{p} \text { value }<0.05 \text { as statistically significant. } \\
\text { a adjusted for the effects of alcohol drinking. } \\
{ }^{\mathrm{b}} \mathrm{p}=0.027 \\
{ }^{\mathrm{c}} \mathrm{p}=0.048\end{array}$} \\
\hline
\end{tabular}

To elucidate the relationship between the progress of clinical status and level of clinical pathological markers in patients with HCC, we analyzed the levels of common clinical pathological markers of HCC such as a-fetoprotein (AFP), aspartate aminotransferase (AST), and alanine aminotransferase (ALT) associated with ADAM10 genotypic frequencies. Table 5 presents the associations of ADAM10 genotypic frequencies with HCC laboratory status. After adjustment for alcohol consumption, $\mathrm{HBsAg}$, and anti-HCV, a significant association was observed between the ADAM10 rs653765 polymorphism and a-fetoprotein $(p=0.017)$. Moreover, we observed a significant association between rs2054096 polymorphic frequency and AST $(\mathrm{p}=0.020)($ Table 5).

Table 4. Odds ratio (OR) and $95 \%$ confidence interval $(\mathrm{Cl})$ of clinical status and ADAM 10 rs653765 genotypic frequencies in 333 HCC patients.

\begin{tabular}{|c|c|c|c|c|}
\hline \multirow[t]{2}{*}{ Variable } & \multicolumn{4}{|c|}{ Genotypic frequencies } \\
\hline & $\begin{array}{l}\text { GG } \\
(\mathrm{N}=236)\end{array}$ & $\begin{array}{l}\mathrm{GA}+\mathrm{AA} \\
(\mathrm{N}=97)\end{array}$ & OR $(95 \% \mathrm{CI})$ & AOR $(95 \% \mathrm{CI})^{\mathrm{a}}$ \\
\hline \multicolumn{5}{|l|}{ Clinical Stage } \\
\hline Stage I/II & $166(70.3 \%)$ & $62(63.9 \%)$ & 1.00 & 1.00 \\
\hline Stage III/IV & $70(29.7 \%)$ & $35(36.1 \%)$ & $1.339(0.812-2.207)$ & $1.338(0.811-2.207)$ \\
\hline \multicolumn{5}{|l|}{ Tumor size } \\
\hline$\leqq \mathrm{T} 2$ & $166(70.3 \%)$ & $64(66.0 \%)$ & 1.00 & 1.00 \\
\hline$>\mathrm{T} 2$ & $70(29.7 \%)$ & $33(34.0 \%)$ & $1.223(0.738-2.025)$ & $1.225(0.739-2.031)$ \\
\hline \multicolumn{5}{|l|}{$\begin{array}{l}\text { Lymph node } \\
\text { metastasis }\end{array}$} \\
\hline No & $231(97.9 \%)$ & $93(95.9 \%)$ & 1.00 & 1.00 \\
\hline Yes & $5(2.1 \%)$ & $4(4.1 \%)$ & 1.987 (0.522-7.563) & $2.302(0.591-8.968)$ \\
\hline \multicolumn{5}{|c|}{ Distant metastasis } \\
\hline No & $229(97.0 \%)$ & $88(90.7 \%)$ & 1.00 & 1.00 \\
\hline Yes & $7(3.0 \%)$ & $9(9.3 \%)$ & $\begin{array}{l}3.346 \\
(1.209-9.259)^{b}\end{array}$ & $\begin{array}{l}3.634 \\
(1.297-10.179) c\end{array}$ \\
\hline \multicolumn{5}{|c|}{ Vascular invasion } \\
\hline No & $192(81.4 \%)$ & $84(86.6 \%)$ & 1.00 & 1.00 \\
\hline Yes & $44(18.6 \%)$ & $13(13.4 \%)$ & $0.675(0.346-1.320)$ & $0.679(0.347-1.328)$ \\
\hline \multicolumn{5}{|c|}{ Child-Pugh grade } \\
\hline 0 or $\mathrm{A}$ & $176(74.6 \%)$ & $79(81.4 \%)$ & 1.00 & 1.00 \\
\hline $\mathrm{B}$ or $\mathrm{C}$ & $60(25.4 \%)$ & $18(18.6 \%)$ & $0.668(0.371-1.206)$ & $0.675(0.374-1.219)$ \\
\hline \multicolumn{5}{|l|}{ HBsAg } \\
\hline Negative & $143(60.6 \%)$ & $54(55.7 \%)$ & 1.00 & 1.00 \\
\hline Positive & $93(39.4 \%)$ & $43(44.3 \%)$ & $1.224(0.759-1.975)$ & $1.226(0.759-1.980)$ \\
\hline \multicolumn{5}{|l|}{ Anti-HCV } \\
\hline Negative & $126(54.8 \%)$ & $52(53.6 \%)$ & 1.00 & 1.00 \\
\hline Positive & $110(45.2 \%)$ & $45(46.4 \%)$ & $0.991(0.617-1.592)$ & $0.985(0.613-1.584)$ \\
\hline \multicolumn{5}{|c|}{ Liver cirrhosis } \\
\hline Negative & $42(17.8 \%)$ & $17(17.5 \%)$ & 1.00 & 1.00 \\
\hline Positive & $194(82.2 \%)$ & $80(82.5 \%)$ & $1.019(0.548-1.895)$ & $1.035(0.555-1.928)$ \\
\hline \multicolumn{5}{|c|}{$\begin{array}{l}\text { The ORs with analyzed by their } 95 \% \text { CIs were estimated by logistic regression } \\
\text { models. }\end{array}$} \\
\hline \multicolumn{5}{|c|}{$\begin{array}{l}>\mathrm{T} 2 \text { : multiple tumor more than } 5 \mathrm{~cm} \text { or tumor involving a major branch of the } \\
\text { portal or hepatic vein(s) }\end{array}$} \\
\hline \multicolumn{5}{|c|}{${ }^{*} \mathrm{p}$ value $<0.05$ as statistically significant. } \\
\hline \multicolumn{5}{|c|}{ a adjusted for the effects of alcohol drinking. } \\
\hline \multicolumn{5}{|l|}{${ }^{\mathrm{b}} \mathrm{p}=0.020$} \\
\hline${ }^{\mathrm{c}} \mathrm{p}=0.014$ & & & & \\
\hline
\end{tabular}

Table 5. Association of ADAM 10 genotypic frequencies with the $\mathrm{HCC}$ laboratory findings.

\begin{tabular}{lllll}
\hline Characteristic & $\begin{array}{l}\text { a-Fetoprotein } \\
(\mathrm{ng} / \mathrm{mL})\end{array}$ & AST (IU/L) & ALT (IU/L) & AST/ALT ratio \\
\hline rs514049 & & & & \\
AA & $593.9 \pm 167.8$ & $49.80 \pm 4.03$ & $45.98 \pm 3.20$ & $1.21 \pm 0.02$ \\
AC+CC & $1265.6 \pm 964.7$ & $44.19 \pm 4.72$ & $40.65 \pm 4.33$ & $1.18 \pm 0.04$ \\
p value & 0.494 & 0.366 & 0.323 & 0.492 \\
p value & 0.248 & 0.634 & 0.569 & 0.657 \\
rs653765 & & & & \\
GG & $379.1 \pm 125.1$ & $46.32 \pm 3.31$ & $44.58 \pm 3.26$ & $1.21 \pm 0.03$ \\
GA+AA & $1293.9 \pm 509.4$ & $55.68 \pm 9.16$ & $47.29 \pm 5.96$ & $1.19 \pm 0.03$ \\
p value & 0.082 & 0.337 & 0.690 & 0.483 \\
p value & $0.017^{*}$ & 0.228 & 0.660 & 0.506 \\
rs383902 & & & & \\
TT & $464.7 \pm 155.0$ & $48.38 \pm 3.89$ & $45.08 \pm 3.12$ & $1.21 \pm 0.02$ \\
\hline
\end{tabular}




\begin{tabular}{lllll}
\hline TC+CC & $1194.5 \pm 517.1$ & $51.50 \pm 8.47$ & $46.34 \pm 6.67$ & $1.20 \pm 0.03$ \\
p value & 0.177 & 0.737 & 0.864 & 0.886 \\
p value $^{b}$ & 0.067 & 0.699 & 0.844 & 0.894 \\
rs2054096 & & & & \\
TT & $619.2 \pm 367.9$ & $39.91 \pm 2.51$ & $41.92 \pm 3.62$ & $1.18 \pm 0.03$ \\
TA+AA & $680.6 \pm 205.7$ & $52.90 \pm 4.98$ & $46.81 \pm 3.79$ & $1.21 \pm 0.03$ \\
p value & 0.884 & $0.020^{*}$ & 0.351 & 0.364 \\
p value & 0.876 & 0.104 & 0.439 & 0.454 \\
rs2305421 & & & & \\
AA & $980.8 \pm 412.0$ & $54.31 \pm 8.07$ & $50.17 \pm 5.56$ & $1.16 \pm 0.02$ \\
AG+GG & $487.4 \pm 162.8$ & $46.41 \pm 3.49$ & $42.80 \pm 3.30$ & $1.23 \pm 0.03$ \\
p value $_{\text {p value }^{b}}$ & 0.266 & 0.369 & 0.255 & 0.069 \\
\hline
\end{tabular}

Mann-Whitney U test was used between two groups.

a Mean \pm S.E.

b Adjusted drink, $\mathrm{HBsAg}$, and anti-HCV.

${ }^{*} \mathrm{p}$ value $<0.05$ as statistically significant.

\section{Discussion}

In this study, we demonstrated correlations of ADAM10 SNPs with HCC clinicopathologic characteristics. Revealing studies have suggested the potential role of ADAM10 in cell migration and metastasis in various cancers including HCC. In hypopharyngeal squamous cell carcinoma (HSCC), high expression of ADAM10 was suggested to increase epithelial-mesenchymal transition (EMT) regulation, and promote tumor cell migration and infiltration [23]. In human esophageal squamous cell carcinoma (ESCC), active ADAM10 was suggested to promote the carcinogenesis, invasion, metastasis, and proliferation of ESCC and control invasion and metastasis through shedding E-cadherin activity [24]. In primary uveal melanoma, ADAM10 expression is associated with more rapid metastatic progression $[25,26]$. In human non-small-cell lung cancer, ADAM10 overexpression was suggested to be correlated with cell migration and invasion through activation of the Notch1 signaling pathway [27]. Expression of ADAM10 was also significantly associated with high C-erbB-2 expression, lymph node and distant metastasis, and poor prognosis in gastric cancer [28]. In addition, ADAM10 was suggested to be a potential therapeutic target for treating HCC because reduced ADAM10 expression not only resulted in inhibition of cell proliferation but also decreased the invasion and migration of HepG2 cells [29]. Furthermore, ADAM10 silencing in HepG2 cells was observed to significantly reduce constitutive phosphorylation of phosphoinositide 3-kinase (PI3K) and Akt [30]. Furthermore, ADAM10 was overexpressed in HCC tissues and associated with tumor progression [15] and miR-365 was found to target ADAM10 and suppresses the cell growth and metastasis of HCC [31]. Taken together, these results suggested that the ADAM10 may play crucial role in HCC progression and metastasis. However, information regarding correlations of ADAM10 SNPs to cancer progression and metastasis remain limited and unclear. In the current study, we examined the allele frequency and genotyping of ADAM10 SNPs in patients with HCC and healthy controls. However, ADAM10 SNPs rs514049, rs653765, rs383902, rs2054096, and rs2305421 were not associated with HCC risk (Table 2). We further analyzed the correlations of ADAM10 SNP genotypic frequencies to clinical statuses in 333 patients with HCC. Notably, we observed that rs514049 with the "AC + CC" genotype was associated with a higher risk of lymph node metastasis (Table 3) and rs653765 with the "GA $+\mathrm{AA}^{\prime \prime}$ genotype was associated with a higher risk of distant metastasis (Table 4).

In a study of atherosclerotic cerebral infraction (ACI) conducted among a Chinese population, individuals who carried the ADAM10 SNP rs653765 C $>\mathrm{T}$ mutation in the promoter region were exhibited correlation with higher ADAM10 mRNA levels compared with their WT allele; this suggested that the ADAM10 rs653765 $\mathrm{C}>\mathrm{T}$ polymorphism may be a functional SNP [32]. However, the rs514049 polymorphism of ADAM10 involved in the same study was negatively associated with ACI [32]. Compared with these results, our previous studies have found that the rs653765 genetic variant is associated with distant metastasis. By contrast, the present study found that the ADAM10 rs514049 polymorphism in the patients with HCC was associated with lymph node metastasis (Table 3). This result implies the potential role of ADAM10 SNPs in HCC progression and demonstrated the variety of ADAM10 SNP expression in various diseases. In a study on AD, Bekris et al. reported that the ADAM10 rs514049-rs653765 C-A promoter haplotype was correlated with a higher cerebral spinal fluid sAPPa level in cognitive controls than in patients with $\mathrm{AD}$, especially the rs514049 C allele [19]. Although we did not investigate the ADAM10 rs514049-rs653765 haplotype, ADAM10 rs514049 and rs653765 polymorphic variants were associated with lymph node metastasis and distant metastasis, respectively (Tables 3 and 4). Therefore, the rs514049 in the promoter region may play a role in HCC progression and ADAM10 regulation, and the aforementioned polymorphic rs514049 and rs653765 variants may elucidate a molecular mechanism of overexpressed ADAM10 in HCC tissue and the presence of metastasis [15]. Moreover, the rs653765 polymorphism may be a functional SNP because the rs653765 $\mathrm{C}>\mathrm{T}$ polymorphism is located one base downstream of the potential site for the myc-associated zinc finger protein (MAZ) transcription factor [16]. The ADAM10 rs653765 polymorphism was also associated with the 
development of severe sepsis [17]; however, the risk CC genotype was suggested to have functionally affected the expression level of ADAM10 mRNA, which was accompanied by the upregulation of its substrates [17], compared with the "GA + AA" genotype in HCC being associated with a higher risk of distant metastasis in the present study (Table 4). Although the functions and detailed mechanisms of ADAM10 rs514049 remain uncertain and controversial, rs514049 and rs653765 are involved in HCC disease progression and metastasis, and rs653765 may play a more essential role in regulating ADAM10 expression in HCC and other diseases. Profound ethnic differences and diversity of ADAM10 expression and regulation in various diseases might be responsible for this discrepancy.

AFP and AST are established markers in common liver function tests. AFP is a serum glycoprotein. A fetal liver and fetal yolk sac generated high levels of AFP, which gradually declined to $<10$ $\mathrm{ng} / \mathrm{dl}$ at 300 days after birth [33]. Thereafter, elevated serum AFP levels suggested an underlying pathology that might have been malignant [34]. In addition, increased AST levels may indicate liver damage [35]. In our study, we found that after adjustment for alcohol consumption, $\mathrm{HBsAg}$, and anti-HCV, the ADAM10 rs653765 "GA + AA" genotype was associated with patients with a higher level of AFP ( $p$ $=0.017$, Table 5). Furthermore, we found that the rs2054096 polymorphic "TA + AA" genotype was associated with patients with HCC with higher AST levels $(p=0.020$, Table 5$)$. One study reported that the genetic variants of ADAM10 rs2054096 and rs8027998 were associated with diabetic nephropathy (DN) before but not after adjustment for multiple tests [22]. The common variants in HES1, JAG1, NOTCH3, and ADAM10 were not strongly correlated with $\mathrm{DN}$ in Type 1 diabetes among Caucasian individuals [22]. Compared with these results, the present study, which focused on Taiwanese patients with HCC, revealed no significant differences between rs2054096 and AST after adjustment for alcohol consumption, HBsAg, and anti-HCV (Table 5). Therefore, although the impact and direct links of ADAM10 rs2054096 expression on and to disease remain limited and uncertain, ADAM10 rs2054096 may to some extent participate in regulating ADAM10 expression with rs514049 and rs653765, especially rs653765 because its $\mathrm{C}>\mathrm{T}$ mutation in the promoter region was associated with higher ADAM10 mRNA levels in patients with ACI in a previous study [32] and higher AFP levels in the present study (Table 5). Moreover, Murai et al. demonstrated that the cleavage of CD44 catalyzed by ADAM10 may contribute to the invasion and migration of glioblastoma tumors [36]. Our previous study showed that the CD44 rs187115 variant genotypes (AG + GG) were associated with a higher risk of HCC development and progression to late-stage HCC than were the WT carriers [37]. Therefore, a crosstalk of ADAM10 and CD44 polymorphic variants to HCC migration and invasion might exist, and ultimately could lead to poor prognoses of HCC. However, well-designed future studies could elucidate the detailed mechanisms of ADAM10 SNPs in HCC, such as the controversial role of the ADAM10 promoter rs514049 in HCC and ACI.

In conclusion, our study suggested that ADAM10 SNPs are involved in HCC progression. Patients with the ADAM10 SNP rs514049 "AC + CC" and ADAM10 SNP rs653765 "GA + AA" genotypes were associated with higher risks of lymph node metastasis and distant metastasis, respectively. Furthermore, patients with HCC and the rs653765 "GA + AA" genotype were associated with higher levels of AFP, whereas those with the rs2054096 "TA + AA" genotype were associated with higher levels of AST. Thus, ADAM10 SNPs may be used as therapeutic targets for evaluating poor prognoses of HCC.

\section{Acknowledgments}

This study was supported by Chung Shan Medical University and Lo-Hsu Medical Foundation, Lotung Poh-Ai Hospital, Taiwan (CSMU-POHAI105-01). This study was also supported by Chung Shan Medical University, Taiwan (CSMU-INT106-01).

\section{Competing Interests}

The authors have declared that no competing interest exists.

\section{References}

[1] Ferlay J, Soerjomataram I, Dikshit R, Eser S, Mathers C, Rebelo M, Parkin DM, Forman D and Bray F. Cancer incidence and mortality worldwide: sources, methods and major patterns in GLOBOCAN 2012. Int J Cancer 2015; 136: E359-386.

[2] Bray F, Ferlay J, Laversanne M, Brewster DH, Gombe Mbalawa C, Kohler B, Pineros M, Steliarova-Foucher E, Swaminathan R, Antoni S, Soerjomataram I and Forman D. Cancer Incidence in Five Continents: Inclusion criteria, highlights from Volume $\mathrm{X}$ and the global status of cancer registration. Int $\mathrm{J}$ Cancer 2015; 137: 2060-2071.

[3] Bruix J, Han $\mathrm{KH}$, Gores G, Llovet JM and Mazzaferro V. Liver cancer: Approaching a personalized care. J Hepatol 2015; 62: S144-156.

[4] Fan J, Guo W, Sun YF, Shen M, Ma XL, Wu J, Zhang C, Zhou Y, Xu Y, Hu B, Zhang M, Wang G, Chen WQ, Guo L, Lu R, Zhou CH, Zhang X, Shi YH, Qiu SJ, Pan BS, Cao Y, Zhou J and Yang XR. Circulating tumor cells with stem-like phenotypes for diagnosis, prognosis and therapeutic response evaluation in hepatocellular carcinoma. Clin Cancer Res 2018;

[5] Bruix J, Reig M and Sherman M. Evidence-Based Diagnosis, Staging, and Treatment of Patients With Hepatocellular Carcinoma. Gastroenterology 2016; 150: 835-853.

[6] Bruix J, Gores GJ and Mazzaferro V. Hepatocellular carcinoma: clinical frontiers and perspectives. Gut 2014; 63: 844-855.

[7] Wong CM, Tsang FH and $\mathrm{Ng}$ IO. Non-coding RNAs in hepatocellular carcinoma: molecular functions and pathological implications. Nat Rev Gastroenterol Hepatol 2018;

[8] Murphy G. The ADAMs: signalling scissors in the tumour microenvironment. Nat Rev Cancer 2008; 8: 929-941. 
[9] Duffy MJ, McKiernan E, O'Donovan N and McGowan PM. Role of ADAMs in cancer formation and progression. Clin Cancer Res 2009; 15: 1140-1144.

[10] Endres $\mathrm{K}$ and Fahrenholz F. Upregulation of the alpha-secretase ADAM10--risk or reason for hope? FEBS J 2010; 277: 1585-1596.

[11] Mullooly M, McGowan PM, Kennedy SA, Madden SF, Crown J, N OD and Duffy MJ. ADAM10: a new player in breast cancer progression? Br J Cancer 2015; 113: 945-951.

[12] Ko SY, Lin SC, Wong YK, Liu CJ, Chang KW and Liu TY. Increase of disintergin metalloprotease 10 (ADAM10) expression in oral squamous cell carcinoma. Cancer Lett 2007; 245: 33-43.

[13] Jones AV, Lambert DW, Speight PM and Whawell SA. ADAM 10 is over expressed in oral squamous cell carcinoma and contributes to invasive behaviour through a functional association with alphavbeta6 integrin. FEBS Lett 2013; 587: 3529-3534.

[14] Gavert N, Conacci-Sorrell M, Gast D, Schneider A, Altevogt P, Brabletz T and Ben-Ze'ev A. L1, a novel target of beta-catenin signaling, transforms cells and is expressed at the invasive front of colon cancers. J Cell Biol 2005; 168: 633-642.

[15] Zhang W, Liu S, Liu K, Wang Y, Ji B, Zhang X and Liu Y. A disintegrin and metalloprotease (ADAM) 10 is highly expressed in hepatocellular carcinoma and is associated with tumour progression. J Int Med Res 2014; 42: 611-618.

[16] Prinzen C, Muller U, Endres K, Fahrenholz F and Postina R. Genomic structure and functional characterization of the human ADAM10 promoter. FASEB J 2005; 19: 1522-1524.

[17] Cui L, Gao Y, Xie Y, Wang Y, Cai Y, Shao X, Ma X, Li Y, Ma G, Liu G, Cheng W, Liu Y, Liu T, Pan Q, Tao H, Liu Z, Zhao B, Shao Y and Li K. An ADAM10 promoter polymorphism is a functional variant in severe sepsis patients and confers susceptibility to the development of sepsis. Crit Care 2015; 19: 73.

[18] Song JH, Yu JT, Liu M, Yan CZ and Tan L. Genetic association between ADAM10 gene polymorphism and Alzheimer's disease in a Northern Han Chinese population. Brain Res 2011; 1421: 78-81.

[19] Bekris LM, Lutz F, Li G, Galasko DR, Farlow MR, Quinn JF, Kaye JA, Leverenz JB, Tsuang DW, Montine TJ, Peskind ER and Yu CE. ADAM10 expression and promoter haplotype in Alzheimer's disease. Neurobiol Aging 2012; 33: 2229 e2221-2229 e2229.

[20] Bekris LM, Galloway NM, Millard S, Lockhart D, Li G, Galasko DR, Farlow MR, Clark CM, Quinn JF, Kaye JA, Schellenberg GD, Leverenz JB, Seubert P, Tsuang DW, Peskind ER and Yu CE. Amyloid precursor protein (APP) processing genes and cerebrospinal fluid APP cleavage product levels in Alzheimer's disease. Neurobiol Aging 2011; 32: 556 e513-523.

[21] Jian XQ, Wang KS, Wu TJ, Hillhouse JJ and Mullersman JE. Association of ADAM10 and CAMK2A polymorphisms with conduct disorder: evidence from family-based studies. J Abnorm Child Psychol 2011; 39: 773-782.

[22] Kavanagh D, McKay GJ, Patterson CC, McKnight AJ, Maxwell AP, Savage DA and Warren UKGSG. Association analysis of Notch pathway signalling genes in diabetic nephropathy. Diabetologia 2011; 54: 334-338.

[23] Ding C, Zhang Q, Chen Y, Zhang X, Wu P and Zhang Z. Overexpression of A disintegrin and metalloprotease 10 promotes tumor proliferation, migration and poor prognosis in hypopharyngeal squamous cell carcinoma. Oncol Rep 2017; 38: 866-874.

[24] Ma B, Zhang HY, Bai X, Wang F, Ren XH, Zhang L and Zhang MZ. ADAM10 mediates the cell invasion and metastasis of human esophageal squamous cell carcinoma via regulation of E-cadherin activity. Oncol Rep 2016; 35: 2785-2794.

[25] Caltabiano R, Puzzo L, Barresi V, Ieni A, Loreto C, Musumeci G, Castrogiovanni P, Ragusa M, Foti P, Russo A, Longo A and Reibaldi M. ADAM 10 expression in primary uveal melanoma as prognostic factor for risk of metastasis. Pathol Res Pract 2016; 212: 980-987.

[26] Gangemi R, Amaro A, Gino A, Barisione G, Fabbi M, Pfeffer U, Brizzolara A, Queirolo P, Salvi S, Boccardo S, Gualco M, Spagnolo F, Jager MJ, Mosci C, Rossello A and Ferrini S. ADAM10 correlates with uveal melanoma metastasis and promotes in vitro invasion. Pigment Cell Melanoma Res 2014; 27: 1138-1148.

[27] Guo J, He L, Yuan P, Wang P, Lu Y, Tong F, Wang Y, Yin Y, Tian J and Sun J. ADAM10 overexpression in human non-small cell lung cancer correlates with cell migration and invasion through the activation of the Notch1 signaling pathway. Oncol Rep 2012; 28: 1709-1718.

[28] Wang YY, Ye ZY, Li L, Zhao ZS, Shao QS and Tao HQ. ADAM 10 is associated with gastric cancer progression and prognosis of patients. J Surg Oncol 2011; 103: 116-123.

[29] Yue Y, Shao Y, Luo Q, Shi L and Wang Z. Downregulation of ADAM10 expression inhibits metastasis and invasiveness of human hepatocellular carcinoma HepG2 cells. Biomed Res Int 2013; 2013: 434561.

[30] Liu S, Zhang W, Liu K, Ji B and Wang G. Silencing ADAM10 inhibits the in vitro and in vivo growth of hepatocellular carcinoma cancer cells. Mol Med Rep 2015; 11: 597-602.

[31] Liu Y, Zhang W, Liu S, Liu K, Ji B and Wang Y. miR-365 targets ADAM10 and suppresses the cell growth and metastasis of hepatocellular carcinoma. Oncol Rep 2017; 37: 1857-1864.

[32] LiY, Liao F, Yin XJ, Cui LL, Ma GD, Nong XX, Zhou HH, Chen YF, Zhao B and Li KS. An association study on ADAM10 promoter polymorphisms and atherosclerotic cerebral infarction in a Chinese population. CNS Neurosci Ther 2013; 19: 785-794.

[33] Kashyap R, Jain A, Nalesnik M, Carr B, Barnes J, Vargas HE, Rakela J and Fung J. Clinical significance of elevated alpha-fetoprotein in adults and children. Dig Dis Sci 2001; 46: 1709-1713.
[34] Bialecki ES and Di Bisceglie AM. Diagnosis of hepatocellular carcinoma. HPB (Oxford) 2005; 7: 26-34.

[35] Chalupsky K, Kanchev I, Zbodakova O, Buryova H, Jirouskova M, Korinek V, Gregor M and Sedlacek R. ADAM10/17-dependent release of soluble c-Met correlates with hepatocellular damage. Folia Biol (Praha) 2013; 59: 76-86.

[36] Murai T, Miyazaki Y, Nishinakamura H, Sugahara KN, Miyauchi T, Sako Y, Yanagida T and Miyasaka M. Engagement of CD44 promotes Rac activation and CD44 cleavage during tumor cell migration. J Biol Chem 2004; 279: $4541-4550$.

[37] Chou YE, Hsieh MJ, Chiou HL, Lee HL, Yang SF and Chen TY. CD44 gene polymorphisms on hepatocellular carcinoma susceptibility and clinicopathologic features. Biomed Res Int 2014; 2014: 231474. 